\title{
Effects of carbamazepine on spinal cord ischemia
}

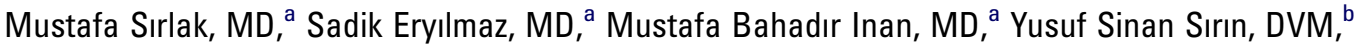 \\ Omer Besaltı, DVM, PhD, ${ }^{c}$ Levent Yazıcıoglu, MD, ${ }^{a}$ Evren Ozcınar, MD, ${ }^{a}$ Esra Erdemlı, MD, ${ }^{d}$ Refik Tasoz, MD, \\ Atilla Halil Elhan, PhD, ${ }^{\mathrm{e}}$ Bulent Kaya, $\mathrm{MD}^{\mathrm{a}}$, and Umit Ozyurda, $\mathrm{MD}^{\mathrm{a}}$
}

From the Department of Cardiovascular Surgery, ${ }^{\mathrm{a}}$ Ankara University School of Medicine, Ankara, Turkey; Department of Veterinary Medicine, ${ }^{\mathrm{b}} 19$ Mayis University, Samsun, Turkey; Department of Veterinary Medicine, ${ }^{\mathrm{c}}$ Ankara University, Ankara, Turkey; Department of Histology and Embryo$\operatorname{logy},{ }^{\mathrm{d}}$ and Department of Biostatistics, Ankara University School of Medicine, Ankara, Turkey.

Financial support was provided by the Turkish Society of Vascular Surgery.

Received for publication Sept 30, 2007; revisions received Nov 28, 2007; accepted for publication Dec 18, 2007.

Address for reprints: Mustafa Bahadır Inan, MD, Ankara University Medical School, Department of Cardiovascular Surgery Ankara-Turkey (E-mail: mbahadirinan@ gmail.com).

J Thorac Cardiovasc Surg 2008;136:103843

\section{$0022-5223 / \$ 34.00$}

Copyright $\odot 2008$ by The American Association for Thoracic Surgery

doi:10.1016/j.jtcvs.2007.12.068
Background: Prophylactic treatment with carbamazepine has been shown to reduce the cerebral damage and neurologic deficit in ischemic conditions. A randomized controlled study based on a rabbit model was designed to study the effect of carbamazepine on a spinal cord ischemic reperfusion injury.

Methods: Thirty New Zealand rabbits were randomly assigned to 1 of the 2 groups ( $\mathrm{n}=15$ per group): group I (control group) and group II (carbamazepine group). Spinal cord ischemia was induced by infrarenal aortic crossclamp for 25 minutes in both groups. Functional evaluation with the Tarlov score during a 2-day observation period and histopathologic assessment of the lumbar spinal cord were performed. Changes in spinal cord morphology were observed with hematoxylin-eosin staining and electron microscopy. Gray matter damage was assessed on the basis of the number of normal neurons in the ventral horn.

Results: Diffuse destruction of gray matter with moderate to severe vacuolization and essentially no normal ganglion cells was observed in the spinal cord of rabbits in the control group, whereas specimens of rabbits assigned to the carbamazepine group showed ganglion cells with normal nuclei and cytoplasm $(P<.0001)$. Neurologic impairment was significantly attenuated in the carbamazepine group compared with the Tarlov scores of the control group $(P<.0001$ at day 2$)$.

Conclusion: Carbamazepine may protect the spinal cord from ischemic reperfusion injury that is associated with ameliorated neurologic and histopathologic results.

$\mathrm{T}$ Temporary or permanent interruption of the blood supply to the spinal cord may cause spinal cord injury manifested by paraplegia, which continues to be a major devastating and unpredictable complication after surgical repair of descending and thoracoabdominal aortic aneurysms. Although the neurologic deficits have significantly decreased in recent times with the progress of surgical adjuncts and pharmacologic interventions, the incidence of paraplegia is still high at $6.6 \%$ to $8.3 \%$ in patients with extent II thoracoabdominal aortic aneurysms. ${ }^{1,2}$ Evidently, longstanding ischemia during aortic clamping and failure to restore flow to the spinal cord will lead to infarction and irreversible neurologic deficits. Additional damage to the spinal cord may occur during the period of reperfusion. This reperfusion injury has been primarily attributed to biochemical causes, such as oxygen free radicals, leukocytes, or other inflammatory mediators. ${ }^{3}$

Several efforts have been focused on solving this problem, which include surgical techniques, pharmacologic intervention, and mechanical methods, such as hypothermia, cerebrospinal fluid drainage, and retrograde venous perfusion. ${ }^{4-7}$ The cellular and molecular mechanisms of ischemic spinal cord injury are not fully understood. Multiple studies have suggested that calcium overload, free radical production, platelet aggregation, neutrophil accumulation, and adhesion after ischemia may contribute to neuronal ischemic spinal cord injury. ${ }^{8-12}$

There have been many reports on the methods of treatment or prevention of ischemic spinal cord injury, ${ }^{4-7}$ but to date, there is no scientifically established method. Carbamazepine (CBZ) is an antiepileptic drug that has been extensively used in 


\section{Abbreviations and Acronyms \\ $\mathrm{CBZ}=$ carbamazepine \\ NMDA $=N$-methyl-d-aspartate}

neurology in the treatment of epilepsies and trigeminal neuralgia, and in psychiatry for the prophylactic treatment of affective and schizoaffective psychosis. It has been shown that preischemic treatment with $\mathrm{CBZ}$ tends to reduce the cerebral damage and neurologic deficit. ${ }^{13}$ Schirrmacher and colleagues ${ }^{13}$ also suggested that $\mathrm{CBZ}$ reduces $\mathrm{Ca}^{+2}$ currents presumably by inhibiting L-type $\mathrm{Ca}^{+2}$ channels in sensory spinal ganglion cells. It also blocks $N$-methyl-d-aspartate (NMDA) induced currents in cultured spinal cord neurons. ${ }^{13}$ NMDA antagonists have been proved to reduce spinal cord injury after ischemia. ${ }^{14}$ This study was designed to investigate the protective efficacy of CBZ on the neurologic and histopathologic outcomes of spinal cord ischemia caused by aortic occlusion in rabbits.

\section{Materials and Methods}

Thirty New Zealand rabbits of either sex, weighing 2.5 to $3.5 \mathrm{~kg}$, were used in the experiments. The animal protocol was approved by the Ethics Review Committee for Animal Experimentation of Ankara University, Faculty of Veterinary.

As a previously described dose ${ }^{15}$ in rabbits, a single dose of $20 \mathrm{mg} / \mathrm{kg} / \mathrm{d}$ of CBZ (Tegretol oral suspension, $100 \mathrm{mg} / 5 \mathrm{~mL}$; Novartis Pharmaceuticals, Basel, Switzerland) was administered by oral gavage with a 3-inch 18-gauge gavage needle to the study group for 5 days before the experiment. During the study period, all animals received humane care in compliance with the Guide for the Care and Use of Laboratory Animals from the Institute of Laboratory Animals, National Research Council (publication no. National Institutes of Health 85-17).

\section{Spinal Cord Ischemia}

The spinal cord ischemia was induced according to the method previously described by Wakamatsu and colleagues. ${ }^{10}$ After an overnight fast with unrestricted access to water, the rabbits were premedicated with atropine sulfate $(0.005 \mathrm{mg} / \mathrm{kg}$, administered subcutaneously) and anesthetized with intramuscularly administered ketamine hydrochloride $(40 \mathrm{mg} / \mathrm{kg})$ and xylazine $(10 \mathrm{mg} / \mathrm{kg})$. Intermittent intravenous readministration of one-quarter doses of the anesthetic agents was rendered to maintain an adequate level of anesthesia and prevent the need for endotracheal intubation and mechanical ventilation. A pediatric facial mask in which oxygen gas flowed at a rate of $200 \mathrm{~mL} / \mathrm{min}$ was placed on each rabbit. The arterial blood pressure was measured via a 24-gauge catheter inserted into the right femoral artery, which was also used for drawing blood samples. With the rabbits in the prone position, the abdomen was opened via a vertical midline incision to expose the abdominal aorta. The aorta and its branches were meticulously dissected from caudal to the left renal artery. Heparin $\left(150 \mathrm{U} / \mathrm{kg}^{-1}\right)$ was given and spinal cord ischemia was produced by occluding the abdominal aorta (caudal to the renal arteries) with an arterial clamp for 25 minutes after a previously established ideal ischemic time. After 25 minutes, the clamp was removed, thus beginning reperfusion. After completion of surgery, the aorta was detected to be intact, and the abdominal wall was closed with 4-0 nylon suture in separate layers. The local infiltration around the wound with $0.25 \%$ bupivacaine hydrochloride was applied for postoperative analgesia. The animals were intramuscularly administered gentamicin (40,000 U) and allowed to recover with free access to food and water. During the procedure, lactated Ringer's solution was infused via an ear vein. Arterial blood pressure and heart beat were continuously monitored, body temperature was continuously monitored with a flexible probe inserted 5 $\mathrm{cm}$ into the rectum, and core temperature was maintained at $38^{\circ} \mathrm{C}$ to $39^{\circ} \mathrm{C}$ by heating lamps. Arterial blood was sampled for determination of blood gases and plasma glucose. The hemodynamic parameters were recorded 20 minutes before ischemia, during ischemia, and 10 minutes after reperfusion.

\section{Neurologic Assessment}

Neurologic recovery was graded by an independent observer, using a modified Tarlov scale: ${ }^{16}$ grade 0 , no movement of the lower limbs; grade 1, minimal movement; grade 2 , good movement but unable to stand; grade 3, able to stand and walk but unable to hop normally; and grade 4 , normal recovery.

Two days after clamping, transcardial $4 \%$ paraformaldehyde in $0.1 \mathrm{~mol} / \mathrm{L}$ phosphate-buffered saline perfusion under $(1 \mathrm{~mL} / 100 \mathrm{~g})$ $30 \%$ pentobarbital $(65 \mathrm{mg} / \mathrm{kg})$ terminal anesthesia method was used for preserving the spinal cords. Laminectomy was performed within 30 minutes after death, and the midlumbar segment of spinal cord was harvested.

\section{Histologic Study}

Light microscopy. To see the histopathologic changes of the spinal cord after ischemia, the spinal cords were removed and fixed in $10 \%$ formalin for 48 hours at room temperature. Samples were then cut transversely at approximately the $\mathrm{L}_{4}-\mathrm{L}_{5}$ level, and after processing with the conventional histotechnologic methods, they were embedded in paraffin; 5 - $\mu$ m-thick sections were stained with the hematoxylin-eosin stain and cresyl violet method for Nissl substance. The number of intact large motor neuron cells in the ventral gray matter region was counted in 5 sections per animals. An observer, who was unaware of animal group and neurologic outcome, examined each slide $(\times 100)$. Classification and quantification of anterior horn motor neurons were done in sections. Features consistent with neuronal injury included vacuolization, eosinophilic cytoplasm, and pyknotic appearance. Cells containing Nissl substance in the basophilic cytoplasm, euchromatin nucleus, and prominent nucleoli were considered viable.

Electron microscopy. Samples to be observed for transmission electron microscopy were fixed in $0.2 \mathrm{~mol} / \mathrm{L}$ phosphate buffer containing $2 \%(\mathrm{w} / \mathrm{v})$ paraformaldehyde and $2.5 \%(\mathrm{v} / \mathrm{v})$ glutaraldehyde for 3 hours at $4^{\circ} \mathrm{C}$. They were washed in $0.1 \mathrm{~mol} / \mathrm{L}$ phosphate buffer and fixed with $1 \%$ osmium tetroxide for 2 hours as secondary fixation. After washing, they were embedded in Araldite 6005 and cut with Leica Ultracut R (Leica Microsystems, Vienna, Austria) ultramicrotome. Semi-thin sections $(1 \mu \mathrm{m})$ were stained by toluidine blue-Azur II to select a region of interest for the following procedures, and thin sections $(60-70 \mathrm{~nm})$ were stained with uranyl acetate and lead citrate. They were examined and photographed using a LEO 906 E TEM (80 kV; Carl Zeiss SMT AG, Oberkochen, Germany). 


\begin{abstract}
Statistics
Group sample sizes of 15 and 15 achieve $81 \%$ power to detect a difference of 1.0 of the neurologic scores between the null hypothesis that both group means are 1.0 and the alternative hypothesis that the mean of group 2 is 2.0 with estimated group standard deviations of 0.90 and 0.90 and a significance level (alpha) of 0.05 using a 2-sided Mann-Whitney test, assuming that the actual distribution is normal. The degree of association between variables was evaluated by Spearman's correlation coefficient. Comparisons between groups for the continuous variables were evaluated by Student $t$ test or Mann-Whitney $U$ test, where applicable. Bonferroni adjustment was applied for multiple comparisons.
\end{abstract}

\section{Results}

\section{Physiologic and Hemodynamic Parameters}

Hemodynamic variables are shown in Table E1. There were no statistical differences in the hemodynamic parameters of the animals in both groups. There were also no differences between the 2 groups regarding $\mathrm{PAO}_{2}, \mathrm{PACO}_{2}$, base excess, and glucose levels (Table E2).

\section{Neurologic Outcomes}

The animals in both groups had normal motor function before the study. An intermediate level of spinal cord ischemia in a rabbit (ie, 20-21 minutes) will usually result in full return of neurologic function after restoration of blood flow to the spinal cord, and the rabbit will be able to hop normally and show no functional change; however, this is often (71\%) followed by the onset of recurrent and progressive paraplegia within 14 to 48 hours. ${ }^{17}$

For this reason, we Tarlov scored the animals 48 hours after reperfusion and noted the final changes. After reperfusion, although none of the animals reached a Tarlov score of 2 in the control group, 2 animals reached a Tarlov score of 3 and 5 animals reached a Tarlov score of 2 in the study group (Figure E1). The mean scores were significantly higher in the CBZ group $(1.6 \pm 0.7$ vs $0.4 \pm 0.5 ; P<.0001)$ (Table E3). There was a significant negative correlation between the Tarlov Score and the percentage of dead total neurons $(\mathrm{r}=$ $-0.627, P<.001)$.

\section{Histopathologic Examination}

Although there were no normal neuron cells in the control group, the mean number of the normal neurons of CBZ group was $57.6 \pm 79.3(P=.0001)$. The mean numbers of the necrotic motor neurons were higher in the control group without statistical significance $(113.8 \pm 16.3$ vs $90.0 \pm 35.7 ; P=$ .061). After calculation of the percentage of necrotic cells in both groups, this percentage was significantly higher in the control group $(100.0 \pm 0.0$ vs $71.1 \pm 35.1 ; P<.001$ (Table E3).

Representative topographic photomicrographs of sections from the control group and CBZ group are shown in Figure 1, $A$ and $B$, respectively. In spinal cord sections from the control group, all the ventral horn neurons of the spinal cord demonstrated shrinkage of the cell body, pyknosis of the nucleus, disappearance of the nucleolus, and loss of Nissl substance, with intense eosinophilia of the cytoplasm (red neuron) (Figure 1,C). The loss of the Nissl substance in the cell body (chromatolysis) was also detected with cresyl violet stain (Figure 1,D). In the CBZ group, the number of normal neurons between the necrotic neurons was high; this finding was statistically significant $(P<.0001)$. The normal neurons were characterized by large perikarya with abundant Nissl substance and large nuclei with prominent single nucleoli (Figure 1,E and $F$ ).

In ultrastructural examinations of the groups, the control group showed necrotic neurons with a pyknotic nucleus and disappearance of the nucleolus, but in the CBZ group, the ultrastructural appearance of the neurons was like that of normal neurons (Figure 2).

\section{Discussion}

Spinal cord injury remains a serious problem after operations on the descending and thoracoabdominal aorta. Despite various surgical and pharmacologic approaches to minimize the risk of paraplegia, no methods have effectively prevented this complication. ${ }^{1}$

The mechanism of motor neuronal cell death after spinal cord ischemia and reperfusion has been explored through molecular, cellular, and genetic aspects, but it has not been identified. ${ }^{11}$ Some patients undergoing thoracoabdominal aneurysm repair, with no neurologic deficit, develop delayed-onset paraplegia 1 to 5 days later. The cause of this latter phenomenon is poorly understood, but it has been attributed to postoperative hypotension, embolization to the anterior spinal artery, occlusion of a reimplanted intercostal artery, or anterior spinal artery thrombosis. ${ }^{17}$ The precise pathophysiology of this phenomenon, however, has not been identified. The observation of such delayed neurologic deficits suggests the presence of additional mechanisms of spinal cord injury that might include cord edema in a confined space, cytotoxic action from leukocytes or microglia, vasoconstriction from arachidonic acid metabolites, and free-radical injury from metabolic by-products of ischemia. ${ }^{18-21}$

Evidence is gathering that a various combination of factors induce over-accumulation of intracellular calcium, which triggers proteases, lipase, protein kinase $\mathrm{C}$, nitric oxide synthase, endonucleases, altered gene transcription, and release of free radicals, eventually producing neuronal injury and death. ${ }^{4}$

Ouardouza and colleagues ${ }^{22}$ concluded that reducing $\mathrm{Ca}^{2+}$ import through reverse $\mathrm{Na}^{+} / \mathrm{Ca}^{2+}$ exchange, reducing influx through L-type $\mathrm{Ca}^{2+}$ channels, and indirectly inhibiting $\mathrm{Ca}^{2+}$ release from the endoplasmic reticulum attenuated spinal cord dorsal column ischemia in vitro. Pharmacologic openers of mitochondrial triphosphate-sensitive potassium (mitoKATP) channels (diazoxide) resulted in significant improvement in neurologic outcome in a model of spinal cord ischemia by a preconditioning effect. ${ }^{23}$ 

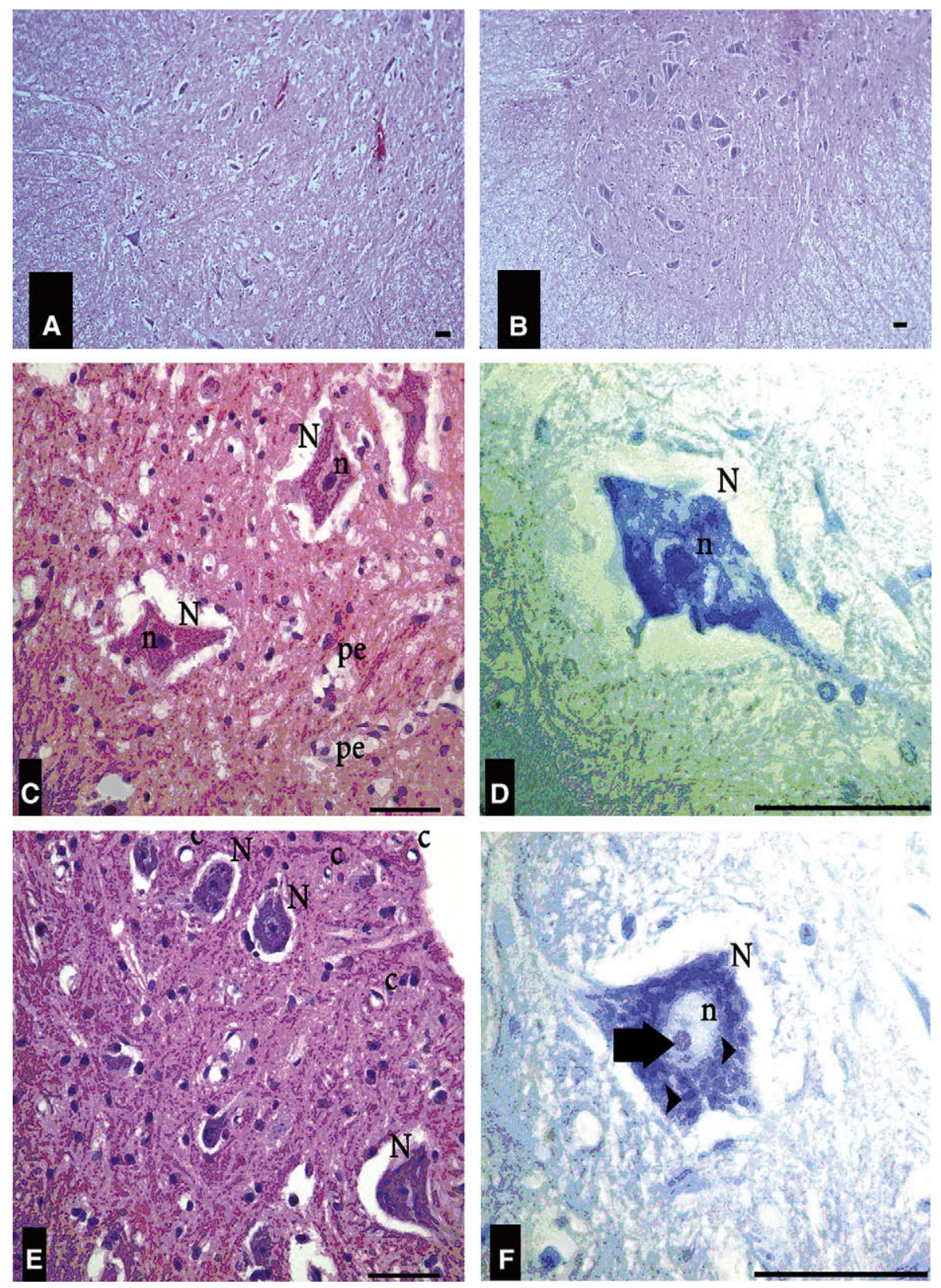

Figure 1. Histologic appearance of sections of spinal cord ventral horn in light microscopy. Topographic photomicrographs of sections in control group (A) and CBZ group (B). C, Necrotic red neurons with pyknotic nucleus and perivascular edema in control group with hematoxylin-eosin stain. D, Loss of Nissl bodies is evident by cresyl violet stain in control group. $E$, Intact neurons and capillaries have normal appearance in CBZ group with hematoxylineosin stain. F, Euchromatin large nucleus, prominent nucleolus (arrow), and Nissl bodies (arrowhead) are shown with cresyl violet stain in CBZ group. Bar scale $=50 \mathrm{~nm}$. $N$, Neuron; n, pyknotic nucleus; c, capillaries; pe, perivascular edema.
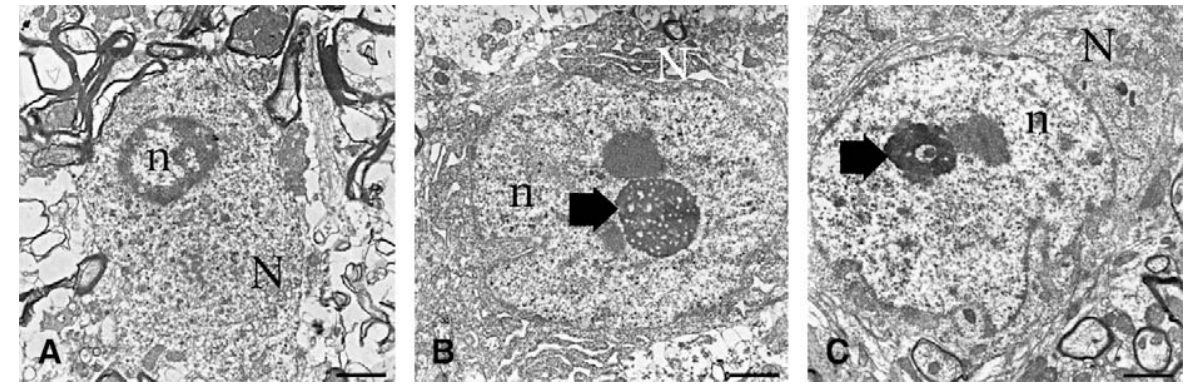

Figure 2. Ultrastructural examination of spinal cord ventral horn in electron microscopy. A, Necrotic neuron in control group; pyknotic nucleus. Other organelles could not be detected. $B$, Examination of viable neuron in CBZ group with euchromatin nucleus and prominent nucleolus (arrow). C, Normal ultrastructure of the spinal cord anterior horn neuron. Bar scale $=10 \mu \mathrm{m}$. N, Neuron; $n$, pyknotic nucleus. 
In a recent study, ${ }^{24}$ both retrograde and systemic adenosine $\mathrm{A}_{2 \mathrm{~A}}$ agonist therapies were effective in attenuating ischemic spinal cord injury. The findings of Crown and $\mathrm{Grau}^{25}$ indicate that serotonergic systems normally protect spinal cord plasticity from the deleterious effects of uncontrollable stimulation.

Glutamate is the major excitatory neurotransmitter in the central nervous system of vertebrates. Under normal conditions, neurons are exposed to physiologic concentrations of glutamate in the course of excitatory neurotransmission. Such exposure is not injurious. During ischemia, a massive release of glutamate into the extracellular space ${ }^{26}$ coupled with a decreased capacity of metabolically impaired glia to transport glutamate augments injury and facilitates neuronal death. The study of Mills and colleagues ${ }^{4}$ was conducted to collect the excitatory amino acids by microdialysis fibers inserted close to the impact region of the spinal cord and effectively decreased their levels in a rat model of spinal cord injury.

It has been shown that CBZ has all these aforementioned properties: It inhibits $\mathrm{Ca}^{2+}$ channels, enhances 4-aminopyridine-sensitive potassium currents in cortical neurons, acts as an antagonist of adenosine $A_{1}$ receptors, attenuates cyclic adenosine monophosphate production, induces the release of serotonin, and inhibits the release of glutamate. ${ }^{21}$

CBZ also blocks NMDA-activated membrane currents in cultured neurons in a dose-dependent fashion. The NMDA receptor-activated channel, which is blocked at physiologic concentrations of $\mathrm{Mg}^{2+}$ at resting membrane potential, can be activated by glutamate in depolarized neurons. ${ }^{27,28}$ Therefore, the block of NMDA-evoked membrane currents in cultured neurons may contribute to the clinical effectiveness of CBZ.

With anoxia, ischemia, and mitochondrial dysfunction, the primary factor detrimental to neurons is insufficient energy supply relative to their requirement. Accordingly, reduction of energy demand is a rational neuroprotective strategy. Down-modulation of voltage-gated $\mathrm{Na}^{+}$-channels is another effective way to reduce adenosine triphosphate demand because a large part of the energy consumed by nerve cells is used for the maintenance and replenishment of ionic gradients (especially $\mathrm{Na}^{+}$gradient) across the cellular membrane. NS-7, a novel $\mathrm{Na}^{+} / \mathrm{Ca}^{2+}$ channel blocker, protected the spinal cord against ischemic insults by preventing neuron necrosis and apoptosis. ${ }^{29} \mathrm{CBZ}$ also blocks neuronal $\mathrm{Na}^{+}$channels and has been shown to be cerebroprotective in various models of cerebral ischemia. It provides significant protection from oxygen deprivation. These effects may be responsible for the neuroprotective effects of $\mathrm{CBZ}$ even under ischemic conditions.

We focused on the therapeutic benefits of CBZ for functional recovery after spinal cord ischemia. There was significant improvement in the neurologic outcomes of rabbits that received CBZ compared with the control group. The CBZ group had higher Tarlov scores than the control animals.
Although none of the animals in the control group were able to stand, 2 animals in the CBZ group were able to stand and walk. It was confirmed in the present study that both motor function scores and the percentage of normal neurons in the anterior spinal cord at 48 hours in the CBZ group were significantly higher than those in the control group.

Histologic examination confirmed the ability of CBZ to limit neuronal degeneration and necrosis in the anterior horn motor neurons. Histologic examination of the spinal cords revealed less evidence of injury in the CBZ group, whereas spinal cords from control animals had evidence of extensive spinal cord injury with central gray matter necrosis, perikaryal shrinkage, vacuolization of anterior horn motor neurons, and Nissl substance dissolution. These morphologic changes developed after ischemia and caused the physiologic and clinical consequences observed after ischemic disturbance. The number of normal neurons at the anterior spinal cord has direct relations with neurologic function, which was manifested by a strong correlation between the final neurologic outcomes and the number of normal neurons at the anterior spinal cord.

Furthermore, previous studies showing that $\mathrm{CBZ}$ is more effective under inflammatory conditions ${ }^{30}$ and that the pharmacokinetic behavior of CBZ was not significantly altered in the early phase of spinal cord ischemia ${ }^{15}$ strengthened our motivation to investigate the efficacy of the drug in spinal cord ischemia.

Ischemia-reperfusion injury may cause glutamate efflux from energy-depleted astrocytes through multiple mechanisms, including reversed glutamate transport and swellingevoked or $\mathrm{Ca}^{2+}$-dependent release. Glutamate also might spill into the white matter from the neighboring ischemic gray matter. Ischemia-induced increases in extracellular glutamate concentration could result in toxic activation of functional AMPA (2-[aminomethyl]phenylacetic acid)/kainate glutamate receptors on oligodendrocytes and astrocytes. Competitive $\mathrm{NMDA}^{27}$ and AMPA/kainate glutamate receptor antagonism has been an efficacious measure in spinal cord ischemia. ${ }^{28}$ In view of the prominent role of NMDA receptor mechanism in gray matter injury, the possible neuroprotective effects of NMDA antagonism of CBZ in spinal cord ischemia on the blockade of glutamate receptors to reduce ischemia-induced spinal cord damage may have a limited therapeutic window. ${ }^{30}$ In the present study, CBZ was tested in a pretreatment fashion. The effectiveness of CBZ in a posttreatment fashion was not examined. We aimed to explore preventive measures that may protect the spinal cord from ischemic insult, and we preferred effective pretreatment to posttreatment.

\section{Conclusions}

Our study demonstrates that premedication with CBZ may improve motor functional recovery after spinal cord ischemia. 


\section{References}

1. Coselli JS, LeMaire SA, Miller CC 3rd, Schmittling ZC, Koksoy C, Pagan J, et al. Mortality and paraplegia after thoracoabdominal aortic aneurysm repair: a risk factor analysis. Ann Thorac Surg. 2000;69:409-14.

2. Safi HJ, Miller CC 3rd, Huynh TT, Estrera AL, Porat EE, Winnerkvist AN, et al. Distal aortic perfusion and cerebrospinal fluid drainage for thoracoabdominal and descending thoracic aortic repair: ten years of organ protection. Ann Surg. 2003;238:372-80.

3. Parks DA, Granger DN. Ischemia-reperfusion injury: a radical view. Hepatology. 1988;8:680-2.

4. Mills CD, Xu GY, McAdoo DJ, Hulsebosch CE. Involvement of metabotropic glutamate receptors in excitatory amino acid and GABA release following spinal cord injury in rat. $J$ Neurochem. 2001;79:835-48.

5. Shi E, Jiang X, Kazui T, Washiyama N, Yamashita K, Terada H. Controlled low-pressure perfusion at the beginning of reperfusion attenuates neurologic injury after spinal cord ischemia. J Thorac Cardiovasc Surg. 2007; 133:942-8.

6. Guo G, Bhat RN. p 38a MAP kinase mediates hypoxia-induced motor neuron cell death: a potential target of minocycline's neuroprotective action. Neurochem Res. 2007;32:2160-6.

7. Pocar M, Rossi V, Addis A, Monaco A, Sichel S, Addis F, et al. Spinal cord retrograde perfusion. J Card Surg. 2007;22:124-8.

8. Danielisova V, Chavko M. Comparative effects of the N-Methyl-D-aspartate antagonist MK-801 and the calcium channel blocker KB-2796 on neurologic and metabolic recovery after spinal cord ischemia. Exp Neurol. 1998;149:203-8.

9. Matsumoto M, Iida Y, Wakamastu H, Ohtake K, Nakakimura K, Xiong LZ, et al. The effects of NG-nitro-L-Arginine-Methyl ester on neurologic and histopathologic outcome after transient spinal cord ischemia in rabbits. Anesth Analg. 1999;89:696-702.

10. Wakamatsu H, Matsumoto M, Nakakimura K, Sakabe T. The effects of moderate hypothermia and intrathecal tetracaine on glutamate concentrations of intrathecal dialysate and neurologic and histopathologic outcome in transient spinal cord ischemia in rabbits. Anesth Analg. 1999;88:56-62.

11. Hall ED, Wolf DL. A pharmacological analysis of the pathophysiological mechanisms of posttraumatic spinal cord ischemia. J Neurosurg. 1986;64:951-61.

12. Agee JM, Flanagn T, Blackbourne LH. Reducing postischemic paraplegia using conjugated superoxide dismutase. Ann Thorac Surg. 1991;51:911-5.

13. Schirrmacher K, Mayer A, Walden J, Dusing R, Bingmann D. Effects of carbamazepine on membrane properties of rat sensory spinal ganglion cells in vitro. Eur Neuropsychopharmacol. 1995;5:501-7.

14. Digledine R, Borges K, Bowie D, Traynelis SF. The glutamate receptor ion channels. Pharmacol Rev. 1999;51:7-61.

15. Kermani HR, Ansari M, Karamousian S. The influence of experimental spinal cord injury on carbamazepine pharmacokinetics. Arch Iranian. 2006;3:231-5.
16. Tarlov IM. Acute spinal cord compression paralysis. J Neurosurg. 1972; 36:10-20.

17. Moore WM Jr, Hollier LH. The influence of severity of spinal cord ischemia in the etiology of delayed-onset paraplegia. Ann Surg. 1991; 213:427-32.

18. Hollier LH. Protecting the brain and spinal cord. J Vasc Surg. 1987;5: 524-8.

19. Giulian D. Ameboid microglia as effectors of inflammation in the central nervous system. J Neurosci Res. 1987;18:155-71.

20. Norris DA, Weston WL, Sams WM. The effect of immunosuppression and anti-inflammatory drugs upon monocyte function in vitro. $J \mathrm{Lab}$ Clin Med. 1977;90:569-80.

21. Ambrosio AF, Silva AP, Malva JO, Soares-da-Silva P, Carvalho AP, Carvalho CM. Carbamazepine inhibits L-type $\mathrm{Ca}^{2+}$ channels in cultured rat hippocampal neurons stimulated with glutamate receptor agonists. Neuropharmacology. 1999;38:1349-59.

22. Ouardouza M, Zamponib GW, Barrb W, Kiedrowskic L, Stys PK. Protection of ischemic rat spinal cord white matter: dual action of KB$\mathrm{R} 7943$ on $\mathrm{Na}^{+} / \mathrm{Ca}^{2+}$ exchange and L-type $\mathrm{Ca}^{2+}$ channels. Neuropharmacology. 2005;48:566-75.

23. Caparrelli DJ, Cattaneo SM II, Bethea BT, Shake JG, Eberhart C, Blue ME, et al. Pharmacological preconditioning ameliorates neurological injury in a model of spinal cord ischemia. Ann Thorac Surg. 2002; 74:838-45.

24. Reece BT, Okonkwo DO, Ellman PI, Maxey ST, Tache-Leon C, Warren PS, et al. Comparison of systemic and retrograde delivery of adenosine $\mathrm{A}_{2 \mathrm{~A}}$ agonist for attenuation of spinal cord injury after thoracic aortic cross-clamping. Ann Thorac Surg. 2006;81:902-9.

25. Crown ED, Grau WJ. Evidence that descending serotonergic systems protect spinal cord plasticity against the disruptive effect of uncontrollable stimulation. Exp Neurol. 2005;196:164-76.

26. Benveniste H, Drejer J, Schousboe A, Diemer NH. Elevation of the extracellular concentrations of glutamate and aspartate in rat hippocampus during transient cerebral ischemia monitored by intracerebral microdialysis. J Neurochem. 1984;43:1369-74.

27. Follis F, Blisard K, Varvitsiotis SP, Pett SB Jr, Temes T, Wernly AJ. Competitive NMDA receptor antagonists and spinal-cord ischemia. $J$ Invest Surg. 2000;13:117-21.

28. Shi E, Kazui T, Jiang X, Washiyama N, Suzuki K, Yamashita K, et al. NS-7, a novel $\mathrm{Na}^{+} / \mathrm{Ca}^{2+}$ channel blocker, prevents neurologic injury after spinal cord ischemia in rabbits. J Thorac Cardiovasc Surg. 2005; 129:364-71.

29. Urenjak J, Obrenovitch TP. Neuroprotection-rational for pharmacological modulation of Na+- channels. Amino Acids. 1998;14:151-8.

30. Kanellopoulos GK, Xu GK, Hsu CY, Lu X, Sundt TM, Kouchoukos NT. White matter injury in spinal cord ischemia protection by AMPA/kainate glutamate receptor antagonism. Stroke. 2000;31: 1945-52. 


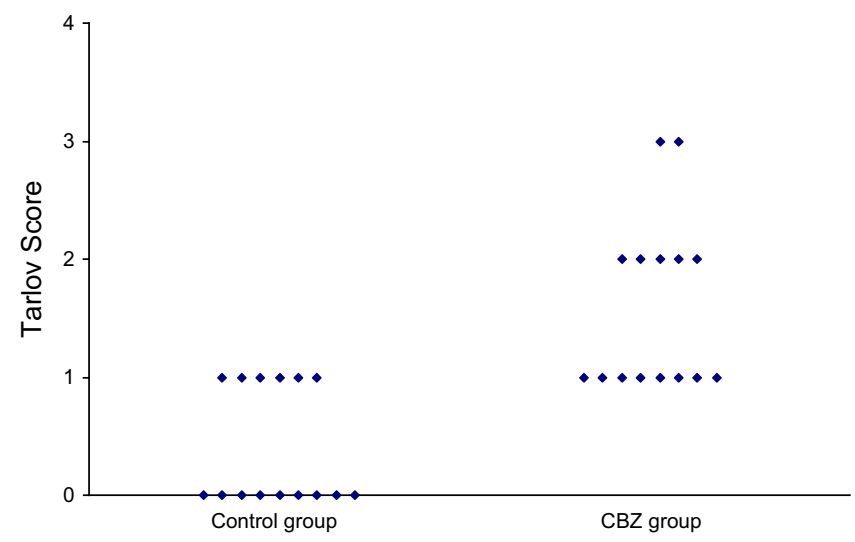

Figure E1. Scatter plot of the Tarlov score for each group. $C B Z$, Carbamazepine. 
TABLE E1. Hemodynamic parameters

\begin{tabular}{|c|c|c|c|c|c|}
\hline & \multicolumn{2}{|c|}{ Control group } & \multicolumn{2}{|c|}{ CBZ group } & \multirow[b]{2}{*}{$P$} \\
\hline & Mean \pm SD & Median (IOR) & Mean \pm SD & Median (IOR) & \\
\hline$H R^{a}$ & $294.2 \pm 10.4$ & $297.0(10.0)$ & $293.1 \pm 12$ & $293.0(10.75)$ & .880 \\
\hline$H R^{b}$ & $266.8 \pm 9.4$ & $270.0(4.0)$ & $265.8 \pm 10.2$ & $267.0(8.5)$ & .806 \\
\hline $\mathrm{HR}^{\mathrm{c}}$ & $277.2 \pm 10.1$ & $280.0(15.0)$ & $277.0 \pm 11.2$ & $277.5(15.0)$ & .838 \\
\hline $\mathrm{MAP}^{\mathrm{a}}$ & $84.6 \pm 2.7$ & $85.0(5.0)$ & $84.5 \pm 2.1$ & $84.0(3.0)$ & .941 \\
\hline $\mathrm{MAP}^{\mathrm{b}}$ & $18.0 \pm 1.0$ & $18.0(2.0)$ & $17.6 \pm 1.2$ & $18.0(3.0)$ & .389 \\
\hline $\mathrm{MAP}^{\mathrm{c}}$ & $83.8 \pm 3.1$ & $84.0(5.0)$ & $84.0 \pm 2.3$ & $83.0(4.0)$ & .845 \\
\hline $\operatorname{Trec}^{a}$ & $39.1 \pm 0.3$ & $39.1(0.50)$ & $39.1 \pm 0.3$ & $39.0(0.55)$ & .910 \\
\hline Trec $^{b}$ & $38.6 \pm 0.2$ & $38.6(0.50)$ & $38.6 \pm 0.2$ & $38.5(0.53)$ & .775 \\
\hline $\operatorname{Trec}^{c}$ & $38.9 \pm 0.2$ & $39.0(0.30)$ & $39.0 \pm 0.2$ & $39.0(0.35)$ & .578 \\
\hline
\end{tabular}

$C B Z$, Carbamazepine; $S D$, standard deviation; $I Q R$, interquartile range; $H R$, heart rate; $M A P$, mean arterial pressure; Trec, rectal temperature. ${ }^{a} 20$ minutes before ischemia. ${ }^{b}$ During ischemia. ${ }^{\mathrm{c}} 10$ minutes after reperfusion. 
TABLE E2. Physiologic parameters

\begin{tabular}{|c|c|c|c|c|c|}
\hline & \multicolumn{2}{|c|}{ Control group } & \multicolumn{2}{|c|}{ CBZ group } & \multirow[b]{2}{*}{$P$} \\
\hline & Mean \pm SD & Median (IOR) & Mean \pm SD & Median (IOR) & \\
\hline $\mathrm{pH}^{\mathrm{a}}$ & $7.34 \pm 0.019$ & $7.34(0.03)$ & $7.34 \pm 0.017$ & $7.35(0.03)$ & .866 \\
\hline $\mathrm{pH}^{\mathrm{b}}$ & $7.33 \pm 0.007$ & $7.33(0.01)$ & $7.33 \pm 0.007$ & $7.33(0.01)$ & .786 \\
\hline $\mathrm{pH}^{\mathrm{c}}$ & $7.32 \pm 0.007$ & $7.32(0.01)$ & $7.32 \pm 0.008$ & $7.32(0.02)$ & .623 \\
\hline $\mathrm{PCO}_{2}{ }^{\mathrm{a}}$ & $38.0 \pm 3.0$ & $39.0(5.0)$ & $38.0 \pm 2.9$ & $38.0(4.0)$ & 1.000 \\
\hline $\mathrm{PCO}_{2}{ }^{\mathrm{b}}$ & $37.84 \pm 0.18$ & $37.9(0.30)$ & $37.87 \pm 0.12$ & $37.9(0.20)$ & .898 \\
\hline $\mathrm{PCO}_{2}{ }^{\mathrm{C}}$ & $37.73 \pm 0.18$ & $37.8(0.30)$ & $37.76 \pm 0.12$ & $37.7(0.20)$ & .932 \\
\hline $\mathrm{PO}_{2}{ }^{\mathrm{a}}$ & $412.8 \pm 45.0$ & $417.0(55.0)$ & $420.8 \pm 44.2$ & $427.0(74.0)$ & .627 \\
\hline $\mathrm{PO}_{2}^{\mathrm{b}}$ & $411.5 \pm 6.55$ & $413.0(12.0)$ & $415.4 \pm 4.81$ & $417.0(9.0)$ & .076 \\
\hline $\mathrm{PO}_{2}{ }^{\mathrm{C}}$ & $413.9 \pm 6.00$ & $415.0(11.0)$ & $417.7 \pm 5.6$ & 419.0 (11.0) & .090 \\
\hline Base excess ${ }^{a}$ & $-2.55 \pm 0.51$ & $-2.70(0.80)$ & $-2.50 \pm 0.56$ & $-2.50(1.10)$ & .771 \\
\hline Base excess ${ }^{b}$ & $-2.89 \pm 0.09$ & $-2.90(0.20)$ & $-2.88 \pm 0.09$ & $-2.90(0.10)$ & .723 \\
\hline Base excess ${ }^{c}$ & $-2.69 \pm 0.09$ & $-2.70(0.20)$ & $-2.68 \pm 0.09$ & $-2.70(0.10)$ & .723 \\
\hline Glucose $e^{a}$ & $128.4 \pm 8.0$ & $128.0(11.0)$ & $128.6 \pm 6.4$ & $128.0(6.0)$ & .941 \\
\hline Glucose $^{b}$ & $130.9 \pm 9.12$ & $130.0(8.0)$ & $131.3 \pm 9.97$ & $130.0(10.0)$ & .739 \\
\hline Glucose $^{c}$ & $140.9 \pm 8.92$ & $140.0(8.0)$ & $140.7 \pm 9.94$ & $140.0(10.0)$ & .939 \\
\hline
\end{tabular}

$C B Z$, Carbamazepine; $S D$, standard deviation; IOR, interquartile range. ${ }^{\mathrm{a}} 20$ minutes before ischemia. ${ }^{\mathrm{b}}$ During ischemia. ${ }^{\mathrm{c}} 10$ minutes after reperfusion. 
TABLE E3. Neurologic parameters

\begin{tabular}{|c|c|c|c|c|c|}
\hline & \multicolumn{2}{|c|}{ Control group } & \multicolumn{2}{|c|}{ CBZ group } & \multirow[b]{2}{*}{$\boldsymbol{P}$} \\
\hline & Mean \pm SD & Median (IOR) & Mean \pm SD & Median (IOR) & \\
\hline Normal neuron (n) & $0.0 \pm 0.0$ & $0.0(0.0)$ & $57.6 \pm 79.3$ & $8.0(143.0)$ & $<.001$ \\
\hline Necrotic neuron (n) & $113.8 \pm 16.3$ & $105.0(26.0)$ & $90.0 \pm 35.7$ & $101.0(55.0)$ & .061 \\
\hline$\%$ necrotic cells & $100.0 \pm 0.0$ & $100.0(0.0)$ & $71.1 \pm 35.1$ & $91.8(66.0)$ & $<.001$ \\
\hline Tarlov score & $0.4 \pm 0.5$ & $0.0(1.0)$ & $1.6 \pm 0.7$ & $1.0(1.0)$ & $<.001$ \\
\hline
\end{tabular}

$C B Z$, Carbamazepine; $S D$, standard deviation; $I Q R$, interquartile range. 